\title{
POLYMYALGIA
}

\section{PROBLEMS OF DIFFERENTIAL DIAGNOSIS}

\author{
BY \\ T. M. CHALMERS, W. R. M. ALEXANDER, AND J. J. R. DUTHIE \\ From the Rheumatic Diseases Unit, Northern General Hospital, Edinburgh
}

Generalized muscular pain may be the presenting symptom of many conditions in which the final diagnosis can be made only after consideration of a wide spectrum of disease. The symptom is commonly associated with disease of bones or joints, but may also occur when skeletal or articular changes are minimal or absent. Diagnosis of cases in this latter category is often difficult and may be reached only after extensive investigation. In recent years there has been increasing interest in the classification of these cases. In some, no obvious pathology can be demonstrated. In others, inflammatory changes in muscle are present and such changes may be accompanied by cutaneous lesions. In a further group, changes in muscle are present but may be obscured by the co-existence of other disorders of connective tissue.

The concept of the syndrome now generally known as polymyalgia rheumatica has evolved gradually. Kersley (1951) described a myalgic syndrome of the aged with signs of systemic disturbance. Bagratuni $(1953,1956)$ reported a group of elderly patients in whom generalized aching pain was associated with fever and loss of weight; he suggested that the syndrome was allied to rheumatoid arthritis and proposed the descriptive term "anarthritic rheumatoid disease". Barber (1957), Gordon (1960), and Todd (1961) observed patients with similar symptoms and suggested the term polymyalgia rheumatica. Paulley and Hughes (1960) expressed the view that such symptoms could be a manifestation of an arteritis of the aged. Bagratuni (1963) has recently reported the course of the disease in some fifty patients with this syndrome, emphasizing its benign prognosis and commenting on the absence of pathological changes in muscle; he found no evidence of the giant-cell arteritis later reported by Alestig and Barr (1963) in seven of ten cases of polymyalgia rheumatica.
Wagner (1863) introduced the term "polymyositis" to describe a fatal case of acute inflammatory disease of muscle, but it should be noted that cutaneous lesions were also present in this patient. This syndrome is now well authenticated and has been extensively reviewed by Walton and Adams (1958) and Pearson and Rose (1960).

Unverricht (1887) used the term "dermatomyositis" to describe cases in which lesions in muscle were associated with changes in skin. Dermatomyositis has been reported more frequently than polymyositis, and Williams (1959), reviewing the literature, noted over 600 cases. An important feature of this condition is its association with malignant disease and Pearson (1962) has estimated that co-existence of dermatomyositis with malignancy may be as much as 18 per cent.

Diffuse involvement of muscle is a fairly constant finding in cases of rheumatoid arthritis. Histological studies have demonstrated irregularlydistributed micro-nodules together with areas of degenerative change in muscle fibre. Clinically obvious myositis, however, is not common. Conversely, articular symptoms were reported by Eaton (1954) in twelve of 41 cases of myositis, and by Walton and Adams (1958) in ten of 40 patients.

In this report, details of 22 patients in whom myalgia was a prominent symptom will be given and the criteria applied in reaching a final diagnosis will be discussed.

\section{Clinical Material}

The series of 22 cases, referred to the Rheumatic Diseases Unit, Northern General Hospital, Edinburgh, over a 2-year period, will be considered in four groups:

(1) The initial complaint was of myalgia, but subsequent investigation yielded no evidence of pathological change in muscle;

(2) A diagnosis of polymyositis was made; 
(3) Polymyositis was associated with cutaneous lesions;

(4) Myositis had developed in patients with some other form of connective tissue disease.

\section{Methods}

Clinical Assessment.-This included estimation of muscle pain, stiffness, tenderness, and weakness. When these features were present they were graded as moderate $(+)$ or marked $(++)$. Cutaneous lesions and articular signs were also noted.

Investigations.-Haemoglobin was measured by the alkali haematin method, 100 per cent. $\mathrm{Hb}$ being equivalent to $14 \cdot 8 \mathrm{~g}$. $\mathrm{Hb} / 100 \mathrm{ml}$. blood.

The erythrocyte sedimentation rate (E.S.R.) was estimated by the modified Westergren method.

The sensitized sheep cell test (SSCT) was performed by the method of Ball (1950) modified by the use of M.R.C. haemagglutination plates in place of test tubes. Agglutination at a titre of $1: 128$ was considered positive. 24-hour urinary creatine excretion was estimated by the method of Jaffe (Varley, 1962).

Serum glutamic-oxalacetic transaminase (SGOT) levels were measured colorimetrically, using a commercial kit obtainable from the Sigma Chemical Company, the results being expressed in Sigma-Frankel units.

Electromyography and skin and muscle biopsies were carried out in a proportion of cases, and in some tests were made to detect the presence of anti-nuclear or L.E. factor in serum.

\section{Results}

The results of all these observations in the four groups are set out in the Table.

\section{Group 1. Polmyalgia (8 patients)}

Clinical Features.-Muscle pain was a very marked feature in five cases, particularly on passive movement of the shoulders or hips. It was associated in four patients with marked muscle tenderness,

TABLE

CLINICAL AND LABORATORY FINDINGS IN A SERIES OF 22 PATIENTS

\begin{tabular}{|c|c|c|c|c|c|c|c|c|c|c|c|c|c|c|}
\hline Group & $\begin{array}{l}\text { Case } \\
\text { No. }\end{array}$ & $\begin{array}{c}\text { Muscle } \\
\text { Pain }\end{array}$ & $\begin{array}{l}\text { Stiff- } \\
\text { ness }\end{array}$ & $\begin{array}{c}\text { Weak- } \\
\text { ness }\end{array}$ & $\begin{array}{c}\text { Muscle } \\
\text { Tender- } \\
\text { ness }\end{array}$ & $\begin{array}{c}\text { Joint } \\
\text { Symp- } \\
\text { toms }\end{array}$ & $\begin{array}{c}\mathrm{Hb} \\
\text { per } \\
\text { cent. } \\
\text { (lowest) }\end{array}$ & $\begin{array}{c}\text { E.S.R. } \\
\text { (mm./hr) } \\
\text { (highest) }\end{array}$ & SSCT & L.E. Cells & $\begin{array}{l}\text { 24-hr } \\
\text { Creatine } \\
\text { Excretion } \\
\text { (mg.) }\end{array}$ & $\begin{array}{l}\text { S.G.O.T. } \\
\text { (S.F. } \\
\text { units) }\end{array}$ & $\begin{array}{l}\text { Electro- } \\
\text { myography }\end{array}$ & Biopsy \\
\hline \multirow{8}{*}{$\begin{array}{l}\text { (1) Foly- } \\
\text { myalgia }\end{array}$} & 1 & ++ & ++ & + & ++ & - & 76 & 117 & $1 / 32$ & - & 0 & 11 & Normal & Normal \\
\hline & 2 & ++ & ++ & + & + & - & 68 & 32 & $1 / 16$ & - & 60 & 28 & Normal & - \\
\hline & 3 & + & ++ & + & - & + & 60 & 65 & $1 / 128$ & - & - & - & Normal & - \\
\hline & 4 & ++ & ++ & + & ++ & - & 58 & 104 & $1 / 64$ & - & 60 & 7 & Normal & - \\
\hline & 5 & + & ++ & + & ++ & - & 69 & 114 & $1 / 256$ & - & 0 & - & Normal & Normal \\
\hline & 6 & ++ & ++ & + & ++ & + & 83 & 54 & $1 / 256$ & - & 22 & 28 & - & Normal \\
\hline & 7 & + & ++ & ++ & + & + & 65 & 124 & $1 / 16$ & - & 0 & 10 & $\begin{array}{c}\text { Not } \\
\text { Diagnost ic }\end{array}$ & Normal \\
\hline & 8 & ++ & ++ & + & + & + & 77 & 99 & $1 / 1024$ & - & - & 12 & - & - \\
\hline \multirow{4}{*}{$\begin{array}{l}\text { (2) Poly- } \\
\text { myositis }\end{array}$} & 9 & + & ++ & ++ & + & - & 79 & 85 & $1 / 16$ & - & 120 & 26 & Positive & - \\
\hline & 10 & + & ++ & - & + & - & 71 & 105 & $1 / 8$ & - & 48 & 42 & Normal & - \\
\hline & 11 & + & + & + & + & + & 81 & 44 & $1 / 8$ & - & 216 & 15 & - & Normal \\
\hline & 12 & + & ++ & ++ & + & + & 65 & 125 & $1 / 32$ & - & 343 & 88 & Positive & - \\
\hline \multirow{4}{*}{$\begin{array}{l}\text { (3) Derma- } \\
\text { tomyositis }\end{array}$} & 13 & + & + & ++ & + & + & 73 & 35 & $1 / 256$ & - & 0 & 56 & Positive & Positive \\
\hline & 14 & + & + & - & - & + & 83 & 13 & $1 / 64$ & - & 0 & 40 & Positive & Positive \\
\hline & 15 & - & + & ++ & + & - & 45 & 27 & $1 / 16$ & - & 120 & 90 & Positive & $\begin{array}{c}\text { Not } \\
\text { Diagnostic }\end{array}$ \\
\hline & 16 & + & + & + & - & + & 84 & 38 & $1 / 512$ & - & 246 & 164 & Positive & - \\
\hline \multirow{6}{*}{$\begin{array}{c}\text { (4)Myosit is } \\
\text { plus } \\
\text { Connective } \\
\text { Tissue } \\
\text { Disease }\end{array}$} & 17 & + & ++ & + & + & - & 74 & 102 & $1 / 16$ & Positive & 61 & 165 & Normal & - \\
\hline & 18 & + & + & + & - & + & 82 & 96 & $1 / 1024$ & Negative & 179 & - & Positive & - \\
\hline & 19 & + & ++ & + & - & + & 83 & 26 & $1 / 1024$ & Negative & 1030 & 80 & Positive & - \\
\hline & 20 & - & ++ & ++ & - & + & 72 & 54 & $1 / 1024$ & Positive & 1200 & 122 & Positive & - \\
\hline & $2 !$ & + & + & + & - & + & 84 & 90 & $1 / 128$ & Negative & 200 & 134 & Positive & - \\
\hline & 22 & + & + & + & + & + & 66 & 15 & $1 / 32$ & - & 146 & 7 & - & - \\
\hline
\end{tabular}


and in three others muscle tenderness of lesser severity was present. Muscle weakness and fatigue were noted by all patients in this group, although specific testing of individual muscle groups indicated true loss of power in only one case. Stiffness was marked in all patients. Articular symptoms were present in four.

Other clinical features noted in some of the patients included weight loss, low-grade pyrexia, epistaxis, transient hypertension, intermittent claudication, and gastrointestinal blood loss. One patient (Case 7) developed an aortic arch syndrome while in hospital, and another gave a history of transient cerebrovascular symptoms.

Investigations.-Moderate anaemia was present in all cases, the average haemoglobin concentration being lower than in the other three groups.

With one exception (Case 2), the E.S.R. was at one time above $50 \mathrm{~mm} . / 1 \mathrm{hr}$ and in four cases was over $100 \mathrm{~mm} . / 1 \mathrm{hr}$.

The SSCT was positive in four patients, although initially no radiological signs of erosive arthritis were found in any case.

Creatine, in small amounts, was present in the urine of three patients and the SGOT was not raised.

Electromyographs were normal or not diagnostic of myositis in the six cases tested, and histology of muscle was normal in the four cases in which biopsy was made.

\section{Illustrative Cases}

Case 1, a 59-year-old boiler-maker, was seen first in September, 1959, complaining of low back pain of sudden onset following a strain at work. Symptoms were attributed to lumbar disk degeneration. A year later he developed dull pain in both thighs followed by pain and weakness in the shoulder girdle.

Examination.-Weakness and tenderness of shoulder and thigh muscles was present. There was also tenderness over the insertion of the deltoid muscles and over the lower cervical and upper dorsal vertebrae.

The E.S.R. was $117 \mathrm{~mm} . / 1 \mathrm{hr}$, and the $\mathrm{Hb}$ concentration gradually fell to 76 per cent. over a period of weeks, although no loss of blood occurred apart from a moderate epistaxis. Radiographs of the skeleton and gastrointestinal and renal tracts revealed no abnormality. The urine did not contain Bence-Jones protein and the sternal myelogram was normal. The SSCT and L.E.-cell tests were repeatedly negative. Creatine was not present in the urine and the SGOT was normal. Electromyograph and muscle biopsy revealed no abnormality. Low grade pyrexia was recorded.

Treatment.-Salicylates and phenylbutazone were not effective. When prednisolone $(20 \mathrm{mg}$. daily) was given, there was dramatic relief of stiffness and pain, a fall in the E.S.R., and a rise in the $\mathrm{Hb}$ concentration. The symptoms have been controlled on $10 \mathrm{mg}$. prednisolone daily for 1 year, and the patient has resumed work.

Case 6, a 64-year-old farm worker, had complained of pain in the muscles of the arms and legs for 3 years. Symptoms were intermittent, but 1 year before admission became severe enough to confine him to bed for 6 weeks, after which he resumed work. There was a severe exacerbation of pain 9 months later. Prednisolone (15 mg. daily) was prescribed, and he was referred to the clinic.

His past history revealed that in 1951, following haematemesis, he had had transient episodes of weakness of the fingers of his right hand and of aphasia for which no cause was found.

Examination.-There was tenderness, weakness, and wasting of the muscles of the shoulders, arms, forearms, and calves. Flexion deformities of the proximal interphalangeal joints were present in both hands; the elbows and knees lacked full extension, and soft-tissue thickening and a small effusion were noted in the left knee.

The E.S.R. was $24 \mathrm{~mm} . / 1 \mathrm{hr}$ and the $\mathrm{Hb}$ concentration was 108 per cent. The SSCT was initially negative, but later a titre of 1:256 was recorded. The SGOT was normal. A small amount of creatine was present in the urine. Degenerative changes were noted in radiographs of the joints. A radiograph of chest was normal.

Treatment.-The dose of prednisolone was gradually reduced, but this was followed by marked increase in pain and stiffness and by a rise in the E.S.R. to $54 \mathrm{~mm}$./1 hr. Low grade fever occurred. Histology of the left biceps brachii was normal.

The dose of prednisolone was increased to $30 \mathrm{mg}$. daily with immediate symptomatic relief and a fall in the E.S.R. Progress was complicated by the development of a respiratory infection and by a deep venous thrombosis, but thereafter improvement was steady. 4 months after discharge from hospital he had almost regained his former functional capacity and his only complaint was of occasional pain in the knees. The dose of prednisolone had been reduced to $15 \mathrm{mg}$. daily and apart from some facial mooning, no side-effects were noted. The haemoglobin was normal, and the E.S.R. $20 \mathrm{~mm} . / 1 \mathrm{hr}$.

Case 7, a 62-year-old woman, complained of pain of 2 years' duration in her shoulders, knees, and ankles.

Examination.-Mild psoriasis was present and a diagnosis of psoriatic arthritis was made, although radiographs of affected joints showed only osteoporosis. The Hb was 95 per cent., the E.S.R. $34 \mathrm{~mm} . / 1 \mathrm{hr}$, and the SSCT negative. 6 months later she developed weakness of trunk and limb girdle muscles, and the $\mathrm{Hb}$ at that time was 65 per cent., and the E.S.R. $102 \mathrm{~mm} . / 1 \mathrm{hr}$. The bone marrow was normoblastic. The L.E.-cell test was negative. Creatine was not present in the urine. The SGOT was normal. Electromyographic examination was suggestive but not diagnostic of acquired myopathy. 
Histological examination of the right pectoralis major revealed only lymphocytic cuffing of one small venule.

Following a brisk epistaxis, the blood pressure, previously recorded in the arms as $150 / 95$, fell to $90 / 50$ $\mathrm{mm}$. $\mathrm{Hg}$ in both. The radial pulses became impalpable. Platelet count and prothrombin level were normal. A harsh systolic murmur was audible above both clavicles, and an aortogram showed occlusion of both subclavian arteries. The patient's symptoms of weakness and stiffness remained unchanged. Low-grade fever was noted. The E.S.R. remained above $100 \mathrm{~mm}$. $/ 1 \mathrm{hr}$.

Treatment.-A diagnosis of generalized arteritis was made and prednisolone given in a dosage of $40 \mathrm{mg}$. daily. There was a dramatic response with relief of symptoms and a fall in the E.S.R. One week later the dose was reduced to $30 \mathrm{mg}$. daily without relapse. The radial pulses could now be felt, and the blood pressure in both arms rose to $100-110 / 80 \mathrm{~mm}$. $\mathrm{Hg}$.

Case 8, a 47-year-old pharmacist, complained of generalized fatigue, muscle pain and stiffness, and pain in one foot, of some 7 weeks' duration. He had had transient pain and swelling in one finger 2 years previously.

Examination.-He was febrile and in considerable pain. A striking feature was the extreme degree of muscle stiffness and myalgia. The small joints in one foot were swollen and tender. The E.S.R. was $99 \mathrm{~mm} . / 1$ $\mathrm{hr}$, and the SSCT strongly positive at a titre of $1: 1024$. He subsequently developed pericarditis, cardiac arrhythmia and pleurisy with effusion. Multiple pulmonary opacities were noted.

Treatment.-Large doses of prednisolone were followed by some initial improvement in his condition, but he died in renal failure 6 to 7 months after the onset of symptoms.

Autopsy.-The appearances were typical of polyarteritis nodosa, involving the lungs, heart, spleen, kidneys, adrenals, prostate, bone marrow, and gastrointestinal tract.

Treatment and Progress.-Two patients improved on a conservative regimen of rest, salicylates, and graded exercises. The others responded only when prednisolone was given. The response was usually dramatic, with rapid symptomatic relief and a fall in the E.S.R. The effective dose was variable, but in most cases $10 \mathrm{mg}$. prednisolone or less was sufficient to control the disease.

One patient (Case 8), whose initial symptoms were predominantly myalgic, died of polyarteritis nodosa. Another (Case 3) developed radiological evidence of an erosive arthritis associated with a positive SSCT. Of the remaining six cases, one has remitted without steroid therapy, and the other five have gained symptomatic relief on varying doses of prednisolone.

\section{Group 2. Polymyositis (4 patients)}

Clinical Features.-All four patients complained of myalgia and stiffness, especially in the shoulder and pelvic girdles, and in the proximal limb muscles. Symptoms varied in severity from case to case, and also in the same individual at different times, being most troublesome after periods of rest. Subjective weakness was a symptom in three members of this group, but in only one was there convincing objective evidence of this. Muscle tenderness wss present in all four. Two patients had articular symptoms, and in one there was a past history of effusion in a knee joint. Neither dysphagia nor weakness of the cervical muscles were noted.

The most significant clinical feature in this group of patients is that their symptoms were ill-defined and the physical findings largely negative. Their complaints might well have been dismissed as functional had not preliminary investigations indicated the need for fuller assessment.

Investigations.-All four cases had moderate anaemia and a raised E.S.R. The SSCT was negative. All had creatinuria and in two the SGOT was elevated. Electromyographs were typical of myositis in two patients, but normal in the one other patient tested. Muscle was histologically normal in the one patient in whom biopsy was made.

\section{Illustrative Case}

Case 9, a 59-year-old housewife, developed muscular pain of gradual onset during prolonged convalescence from an attack of "influenza". The pain was situated in the shoulder and pelvic girdles and back, and was associated with generalized stiffness after rest; 6 months later the symptoms had become more marked and widespread aching pain was also present.

Examination.-She was pale and overweight. No abnormality was found in the peripheral joints, but there was restricted movement of the right shoulder. There was slight tenderness in the trapezii but muscle weakness was not detected.

The E.S.R. was $85 \mathrm{~mm} . / 1 \mathrm{hr}$. The SSCT was negative. Creatinuria was present, but the SGOT was normal. Electromyographs of the deltoid and quadriceps muscles were suggestive of myositis. Other biochemical tests and radiographs were normal.

Treatment.-The patient was treated with rest in bed, salicylates, and graded exercises with some improvement. Over 2 years there has been no progression of her disease, although minor symptoms of stiffness have persisted.

Treatment and Progress.-Two patients improved with conservative measures and after many months 
have had no recurrence of symptoms. One patient, who did not respond to such measures, improved when given prednisolone and has remained free of symptoms on a dose of 5 to $6 \mathrm{mg}$. daily. The remaining patient was already receiving $7.5 \mathrm{mg}$. prednisolone daily when first seen, and her symptoms gradually subsided without increase in dosage.

\section{Group 3. Dermatomyositis (4 patients)}

Clinical Features.-The same symptoms of pain, stiffness, weakness, and tenderness in muscle were encountered among these patients, but the pattern was different. Pain was less marked and was absent in one. Stiffness of varying degree was present in all four. In two cases, subjective and objective weakness and tenderness of muscle were profound, and they also had marked induration and oedema of the skin and subcutaneous tissue, together with facial oedema and violaceous discoloration in the circumorbital area. Articular symptoms were present but not prominent in three of the four patients. All had cutaneous involvement. In two cases erythematous, scaly lesions around the finger nails with some erythematous patches on the dorsum of the hands and forearms were noted. Widespread patchy erythema was present in the two patients in whom induration of the skin was prominent.

Investigations.-The E.S.R. was not markedly raised in this group, but anaemia was constantly found, accentuated in one patient (Case 15) by frank gastrointestinal bleeding. The SSCT was positive in two cases. Creatinuria was present in two of the four cases. The SGOT was raised in all. All showed electromyographic changes typical of myositis. Histological evidence of myositis was obtained in two of three cases in which biopsy was performed. In Case 15 the histological appearances were equivocal.

\section{Illustrative Case}

Case 15, a 68-year-old spinster, gradually developed, over 18 months, stiffness and weakness in her arms, legs, and neck. She became dyspnoeic on effort and when first seen had developed pitting oedema of the right thigh and calf and of the forearms. Her face was swollen and an erythematous rash was present over the dorsum of both hands. Weakness of limb and trunk muscles was apparent. She was referred to the clinic with a diagnosis of fibrositis and congestive cardiac failure.

Examination.-The E.S.R. was $27 \mathrm{~mm} . / 1 \mathrm{hr}$, and the $\mathrm{Hb} 48$ per cent. The SSCT was negative. Creatinuria was present and the SGOT was markedly raised. Electromyographs were typical of myositis.

Occult blood was present in the stools, and a blood transfusion was given after further blood loss from a gastrointestinal haemorrhage. The source of this haemorrhage could not be demonstrated.

Treatment.-Prednisolone was prescribed and a daily dose of $\mathbf{4 0 ~} \mathrm{mg}$. was needed to produce a significant clinical response. Improvement was maintained, however, and the dosage was gradually reduced over a period of months, until 15 months later the patient was free of symptoms on a maintenance dose of $7 \cdot 5 \mathrm{mg}$. prednisolone daily. Haematological and biochemical indices reverted to normal.

Treatment and Progress.-One patient improved satisfactorily with conservative measures. In two others prednisolone was prescribed because of the initial severity of disease; both patients responded well and symptoms and signs have been controlled by less than $10 \mathrm{mg}$. prednisolone daily, 18 months and 3 years respectively after the onset of disease. The fourth patient received prednisolone in view of persistence of symptoms and disease activity, and the response has been satisfactory over a shorter period of observation.

Malignant disease has not been demonstrated in any patient in Group 2 or Group 3, and contractures of muscle have not been observed.

Group 4. Polymyositis and Dermatomyositis in Patients with Other Forms of Connective Tissue Disease (6 patients)

Clinical Features.-Five patients suffered from rheumatoid arthritis, the clinical diagnosis being supported by serological and radiological evidence. The sixth patient developed features of systemic lupus erythematosus.

The clinical picture in this group was extremely varied with no one feature predominating. Muscle pain and tenderness were not prominent, and may have been overshadowed by articular symptoms. Dull aching pain and a feeling of heaviness in the muscles, especially of the thighs, suggested a possible diagnosis of myositis in two cases. In another patient muscle weakness was the most prominent feature.

In three of the patients with rheumatoid arthritis myositis appeared after arthritis was established; in one patient the two conditions developed simultaneously and in another weakness preceded the onset of arthritis. The patient who later developed features of systemic lupus erythematosus presented with muscle pain and stiffness and an atypical rash on the hands and forearms. After admission for investigation she developed pericarditis and pleurisy. 
Skin lesions were noted in four of the six patients in this group. These were predominantly erythematous and scaly and confined to the hands and forearms, although in one case the erythematous areas were more widely distributed. Marked in. duration and oedema of the skin was not observedMild facial erythema and oedema occurred in only two patients.

Investigations.-A raised E.S.R. and moderate anaemia were commonly present in this group. Four of the five patients with rheumatoid arthritis had a positive SSCT. In two cases the L.E.-cell test was positive. Creatinuria was present in all cases and the SGOT was raised in four of the five cases tested. Electromyographs were typical of myositis in four patients and normal in a fifth.

\section{Illustrative Cases}

Case 17, a 53-year-old housewife, complained of generalized muscle pains and stiffness of one month's duration. The muscles of the shoulder girdle, forearms, and calves were involved.

Examination.-There was tenderness of the calf muscles and impairment of grip. No abnormalities were noted in the peripheral joints. The E.S.R. was $77 \mathrm{~mm}$./ $1 \mathrm{hr}$. The SGOT was 60 S.F. units. The muscle symptoms persisted and erythematous areas developed around the finger-nail beds and over the dorsum of her hands. A small effusion was present in the left knee.

She became febrile and developed left-sided chest pain. Pleural and pericardial friction was detected. Pneumococci were cultured from the sputum. A polymorph leucocytosis was present and the L.E.-cell test was positive. The E.S.R. and SGOT remained raised, and on one occasion $61 \mathrm{mg}$. creatine was excreted over a 24-hour period. Excretion after a loading dose of $1 \cdot 32 \mathrm{~g}$. creatine was not, however, greater than 30 per cent. of the amount ingested. Electromyographs of the deltoid and biceps brachii were normal.

Treatment.-The signs and symptoms of pleurisy and pericarditis settled quickly with salicylates and chloroquine and steady improvement followed. When seen 3 months after discharge the patient had no symptoms to report and the clinical findings in muscles, joints, pleura, and heart were normal. There were residual erythematous lesions around the nail beds. The E.S.R. had fallen to $28 \mathrm{~mm}$./1 hr, and the SGOT was normal. The patient appeared to have made an almost complete recovery from an illness with features of dermatomyositis and of lupus erythematosus.

Case 19, a 30-year-old housewife, gave a history of pain in the hands, elbows, shoulders, knees, and hips of 10 months' duration. She also complained of recent fatigue, weakness in the arms and hands, and a feeling of heaviness in the thighs. A rash had been present intermittently on the face and hands.

Examination.-There was marked limitation of finger flexion, with some tightness of the skin over the phalanges. There was tenderness and swelling over the wrist joints and metatarsal heads. The $\mathrm{Hb}$ was 84 per cent. and the E.S.R. $22 \mathrm{~mm} . / 1 \mathrm{hr}$. A clinical diagnosis of rheumatoid arthritis was supported by a stronglypositive SSCT and by the ultimate development of erosions in the hands and feet.

Investigation of muscle stiffness and weakness revealed marked creatinuria and marked elevation of SGOT. Electromyographs were typical of myositis.

This patient thus showed unequivocal evidence of both rheumatoid arthritis and of polymyositis.

Treatment.-Rest in bed, salicylates, and graded exercises were prescribed. Persistent morning stiffness was relieved by a nightly dose of $2.5 \mathrm{mg}$. prednisolone. At re-assessment a year later there was some residual weakness in the thigh muscles, but no creatine was present in the urine and the SGOT was normal.

Treatment and Progress. - The patient who showed features of myositis and systemic lupus erythematosus responded well to a regimen of rest, salicylates, and chloroquine. The other patients in this group all received prednisolone in varying dosage in addition to other measures for the treatment of their rheumatoid arthritis. Muscle symptoms and disease activity were controlled, and no patient has shown any recurrence of myositis.

\section{Discussion}

Clinical features common to all the patients in this series were myalgia and stiffness, weakness, and tenderness in muscle. Their subjective nature made assessment difficult, and differences between the groups were ones of degree rather than of incidence.

A diagnosis was more readily made in those patients with cutaneous manifestations. Articular symptoms, however, were present in a proportion of patients in each group. Pearson (1959) discussed this problem, and described a group of seventeen patients with polymyositis or dermatomyositis; eight of these had articular manifestations, without radiological evidence of erosive arthritis, and in five of six cases tested the latex-fixation or sensitized sheep cell tests were positive. Depending on the predominating feature, a diagnosis of either rheumatoid arthritis with associated myositis, or of polymyositis with articular manifestations might be tenable in such patients.

In the present series the need for more detailed investigation was most apparent in the cases ultimately assigned to Groups 1 or 2, whose initial 
symptoms might have been dismissed as functional but for the finding of a rapid E.S.R. or the presence of anaemia.

The aetiology of the syndrome of polymyalgia rheumatica has not been agreed upon. Among the patients in the first group, the myalgia noted initially in the patient who ultimately proved to have polyarteritis nodosa showed a striking similarity to that seen in other patients in the group. Other manifestations of vascular disturbance included transient hypertension associated with renal impairment, cerebrovascular episodes, epistaxis, gastrointestinal haemorrhage, and, in one patient, sudden occlusion of the subclavian arteries. These features might support the idea that a generalized arteritis was the fundamental pathology in these cases. Certainly no evidence of primary muscle pathology was found.

Moderate anaemia and a raised E.S.R. were present in patients of all groups. It may be noted that, in the four patients with dermatomyositis (Group 2), the E.S.R. was much lower than in the rest.

The more specific tests employed for the demonstration of pathology in muscle included measurement of urinary creatine and of SGOT, electromyography, and skin and muscle biopsy.

Total urinary creatine excretion over a 24-hour period was estimated in all but two cases. Creatine is not normally found in the urine of adult males, nor in that of most adult females (Peters and Van Slyke, 1946), and pathological creatinuria has been defined by Richardson and Shorr (1935) as a condition in which more than 50 to $60 \mathrm{mg}$. of creatine appear in the urine in 24 hours under ordinary conditions of activity and diet.

In an attempt to establish the significance of the results obtained in the present series, creatine excretion was studied in a small control group. The highest total creatine excretion encountered was 20 mg. per 24 hours in an ambulant female with disk degeneration. Six patients with rheumatoid arthritis, who were confined to bed, excreted considerably less than this.

These results would suggest that the creatinuria found in Cases 2, 4, and 10 of the present series was significant, but consideration of various other factors indicates that random estimations of this kind may be misleading. For example, in Case 13, there was unequivocal clinical evidence of a diagnosis of dermatomyositis, supported by electromyographic and biopsy findings, yet creatine was not detected on three separate occasions at a time when the disease was apparently active. On the other hand, in Case 19, in whom myositis was not strongly suspected clinically, creatine excretion was high.
The same reservation was found to be applicable to the SGOT in eighteen of the 22 cases. As an isolated index of muscle pathology this non-specific test proved least helpful in those cases in which the clinical diagnosis was in doubt. Serum enzyme levels did not necessarily correlate well with the degree of creatinuria, although both tests are believed to reflect active breakdown of muscle. It should be added, however, that the SGOT level was helpful as an index of the effect of treatment.

Biopsy of skin or muscle was carried out in eight patients. In only two of these were histological appearances diagnostic, and in both of these electromyography had indicated myositis in the absence of creatinuria. Appearances were normal in the four cases in Group 1 from whom biopsy material was obtained.

Electromyography was carried out in eighteen cases, selecting muscles which were suspected to be involved on clinical grounds. In ten patients the results were compatible with a diagnosis of myositis, and significant creatinuria was found in eight of them. In the two remaining cases, typical electromyographic tracings were associated with slight elevation of the SGOT. In only one of seven cases in which the electromyographs were normal was there any support from other investigations for a diagnosis of myositis. From these results it seems that electromyography is the most useful single investigation which can be employed to establish a diagnosis of myositis.

\section{Summary}

The clinical and laboratory findings in 22 patients presenting with a complaint of myalgia have been described, and the series has been considered in four groups:

(1) Myalgia was not associated with pathological change in muscle;

(2) A diagnosis of polymyositis was made;

(3) Associated skin lesions suggested a diagnosis of dermatomyositis;

(4) Evidence of other disease of connective tissue was present.

The differences in clinical presentation and the value of laboratory tests in differential diagnosis have been discussed.

The response to treatment and the prognosis in each group have been described.

We wish to thank Dr. J. A. Simpson, Neurological Unit, Northern General Hospital, Edinburgh, for carrying out electomyographic studies, Dr. S. L. Tompsett of the 
Biochemistry Department for his assistance in measuring creatine excretion and serum transaminase levels in our patients, and Dr. R. J. G. Sinclair of the Rheumatic Diseases Unit for permission to include one of his cases in this series.

While this work was in progress, one of the authors (T.M.C.) was supported by a grant from Boots Pure Drug Company Limited, and the Rheumatic Diseases Unit was also in receipt of grants from the Medical Research Council and the Empire Rheumatism Council.

\section{REFERENCES}

Alestig, K., and Barr, J. (1963). ～Lancet, 1, 1228.

Bagratuni, L. (1953). Ann. rheum. Dis., 12, 98. (1956). Lancet, 2, 694.

(1963). Brit. med.J., 1, 513.

Ball, J. (1950). Lancet, 2, 520.

Barber, H. S. (1957). Ann. rheum. Dis., 16, 230.

Eaton, L. M. (1954). Neurology, 4, 245.

Gordon, I. (1960). Quart.J. Med., 29, 473.

Kersley, G. D. (1951). "Proc. II Congr. Europ. Rheum., Barcelona", p. 388.

Paulley, J. W., and Hughes, J. P. (1960). Brit. med. J., $2,1562$.

Pearson, C. M. (1959). Arthr. and Rheum., 2, 127.

_ (1962). Bull. rheum. Dis., 12, No. 6, p. 269.

_ and Rose, A. S. (1960). Res. Publ. Ass. nerv. ment. Dis., 38, 422.

Peters, J. P., and Van Slyke, D. D. (1946). "Quantitative Clinical Chemistry. Interpretations", 2nd ed., vol. 1, p. 908. Williams and Wilkins, Baltimore; Baillière, Tindall and Cox, London.

Richardson, H. B., and Shorr, E. (1935). Trans. Ass. Amer. Phycns, 50, 156.

Todd, J. W. (1961). Lancet, $2,1111$.

Unverricht, H. (1887). Z. klin. Med., 12, 533.

Varley, H. (1962). "Practical Clinical Biochemistry", 3rd ed., p. 152. Heinemann, London; Interscience, New York.
Wagner, E. (1863). Arch. Heilkunde, 4, 282.

Walton, J. N., and Adams, R. D. (1958). "Polymyositis." Livingstone, Edinburgh.

Williams, R. G., Jr. (1959). Ann. intern. Med., 50, 1174.

Polymyalgie - Problèmes de diagnostic différentiel

\section{RÉSUMÉ}

On décrit les résultats d'examen clinique et de laboratoire de 22 malades manifestant des myalgies et on les divise en quatre groupes:

(1) Myalgie sans altérations pathologiques du muscle;

(2) Polymyosite diagnostiquée;

(3) Lésions cutanées associées indiquant le diagnostic de dermatomyosite;

(4) Signes de présence d'une autre maladie du tissu conjonctif.

On discute les différences dans la présentation clinique et la valeur des tests de laboratoire pour le diagnostic différentiel.

On décrit la réponse au traitement et le pronostic dans chaque groupe.

\section{Polimialgia - problemas de diagnóstico diferencial}

\section{SUMARIO}

Se describen los hallazgos clínicos y de laboratorio en 22 enfermos que se habian presentado con mialgia y se los divide en cuatro grupos:

(1) Mialgia sin alteraciones patológicas del músculo;

(2) Polimiositis diagnosticada;

(3) Lesiones cutáneas asociadas indicando el diagnóstico de dermatomiositis;

(4) Evidencia de otra enfermedad del tejido conectivo.

Se discuten las diferencias en la presentación clínica y el valor de los tests de laboratorio para el diagnóstico diferencial.

Se describe la respuesta al tratamiento y el pronóstico en cada grupo. 